Document downloaded from:

http://hdl.handle.net/10251/60923

This paper must be cited as:

Nardi, G.; Manet, I.; Monti, S.; Miranda Alonso, MA.; Lhiaubet-Vallet, V. (2014). Scope and limitations of the TEMPO/EPR method for singlet oxygen detection: the misleading role of electron transfer. Free Radical Biology and Medicine. 77:64-70. doi:10.1016/j.freeradbiomed.2014.08.020.

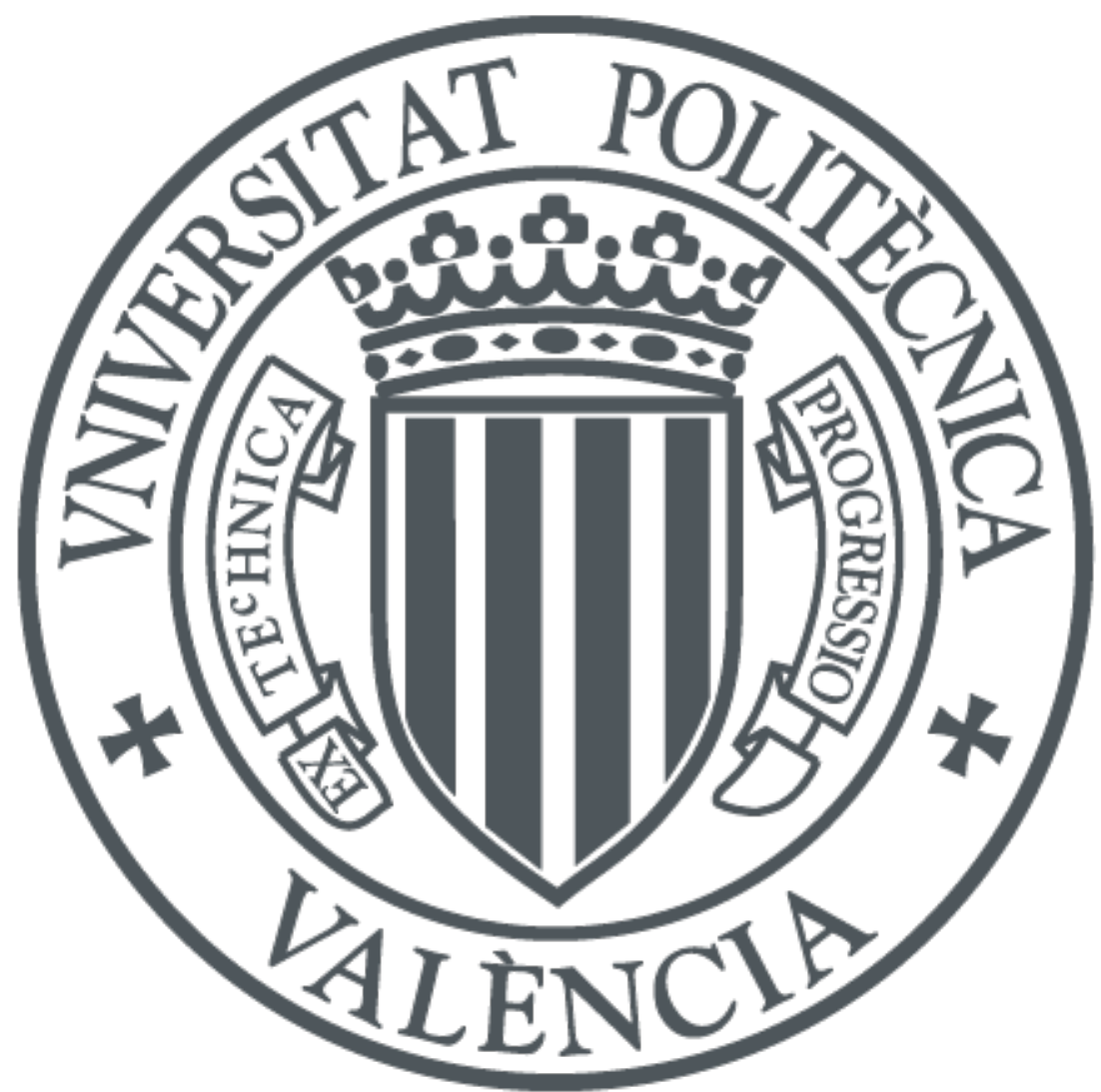

The final publication is available at

http://dx.doi.org/10.1016/j.freeradbiomed.2014.08.020

Copyright Elsevier

Additional Information 


\section{Scope and limitations of the TEMPO/EPR method for singlet oxygen detection: the misleading role of electron transfer}

Giacomo Nardi ${ }^{a}$, Ilse Manet $^{b}$, Sandra Monti ${ }^{b}$, Miguel A. Miranda ${ }^{a}$, Virginie Lhiaubet-Vallet $^{*}{ }^{a}$

a Instituto de Tecnología Química UPV-CSIC, Universitat Politècnica de València, Avda de los Naranjos, s/n , 46022 Valencia, Spain. E-mail addresses: GN: gnardi@itq.upv.es, MAM: mmiranda@qim.upv.es, VL-V: lvirgini@itq.upv.es

${ }^{b}$ Istituto per la Sintesi Organica e la Fotoreattività, CNR, via Piero Gobetti 101, 40129 Bologna, Italy. E-mail addresses: IM: ilse.manet@isof.cnr.it, SM: sandra.monti@isof.cnr.it 


\section{ABSTRACT}

For many biological and biomedical studies, it is essential to detect the production of ${ }^{1} \mathrm{O}_{2}$ and quantify its production yield. Among the available methods, detection of the characteristic $1270 \mathrm{~nm}$ phosphorescence of singlet oxygen by time-resolved near infrared (TRNIR) emission constitutes the most direct and unambiguous approach. An alternative indirect method is electron paramagnetic resonance (EPR) in combination with singlet oxygen probe. This is based on the detection of the TEMPO free radical formed after oxidation of TEMP (2,2,6,6-tetramethylpiperidine) by singlet oxygen. Although the TEMPO/EPR method has been largely employed, it can produce misleading data. This is demonstrated by the present study, where the quantum yields of singlet oxygen formation obtained by TRNIR emission and by the TEMPO/EPR method are compared for a set of well-known photosensitizers. The results reveal that the TEMPO/EPR method leads to significant overestimation of singlet oxygen yield when the singlet or triplet excited state of the photosensitizers are efficiently quenched by TEMP, acting as electron donor. In such case, generation of the $\mathrm{TEMP}^{+\bullet}$ radical cation, followed by deprotonation and reaction with molecular oxygen gives rise to a EPR detectable TEMPO signal that is not associated with singlet oxygen production. This knowledge is essential for an appropriate and error-free application of the TEMPO/EPR method in chemical, biological and medical studies.

KEYWORDS: EPR; photosensitizer; singlet oxygen; TEMPO; time-resolved near infrared emission 


\section{Introduction}

Singlet oxygen (molecular oxygen in a ${ }^{1} \Delta_{\mathrm{g}}$ state or ${ }^{1} \mathrm{O}_{2}$ ) is one of the most important "reactive oxygen species" (ROS). Its reactions include oxidation of lipids [1-2], proteins [3-5] and nucleic acids [6-8], that may trigger a biological damage. This reaction cascade can lead to undesired adverse effects, like drug-induced phototoxicity [9-10], but can also be exploited to produce beneficial effects as in photodynamic therapy [11-12].

Production of ${ }^{1} \mathrm{O}_{2}$ by a photosensitizer is a classical example of photoinduced energy transfer: after absorption of light, the photosensitizer reaches its singlet excited state and subsequently crosses to its triplet excited state. Then, the triplet ground state of molecular oxygen $\left(\mathrm{X}^{3} \Sigma_{\mathrm{g}}{ }^{-}\right)$is promoted to the ${ }^{1} \Delta_{\mathrm{g}}$ state through triplet-triplet energy transfer [13].

For many biological and biomedical studies, it is essential to detect the production of ${ }^{1} \mathrm{O}_{2}$ and quantify its production yield. Among the available methods, detection of the characteristic 1270 $\mathrm{nm}$ phosphorescence of singlet oxygen by time resolved near infrared (TRNIR) emission constitutes the most direct and unambiguous proof [14-15]. However, the required equipment is not always available in biochemical laboratories.

An alternative indirect method that has been widely applied is the use of electron paramagnetic resonance (EPR) in combination with a ${ }^{1} \mathrm{O}_{2}$ probe. Upon reaction with ${ }^{1} \mathrm{O}_{2}$, the trapping molecule gives rise to a detectable spin active species with a distinctive line pattern. Thus, oxidation of TEMP (2,2,6,6-tetramethylpiperidine) by singlet oxygen yields the TEMPO $(2,2,6,6$ tetramethyl-1-piperidinyloxyl) free radical easily detected by EPR (Figure 1) [16]. Although the TEMPO/EPR method has been largely employed [17-25], a systematic investigation of the scope and limitations of this technique has never been performed. For instance, amines are widely known for their quenching ability of excited states, so a probable source of artefacts may be the interaction between the excited photosensitizer and TEMP [26-29]. The aim of the present study is to compare 
the results obtained for the detection and quantification of singlet oxygen by means of the direct method (TRNIR emission) and the indirect ${ }^{1} \mathrm{O}_{2}$ trapping mode (TEMPO/EPR method), using a set of well known photosensitizers. The basis of the TEMPO method and the chemical structure of the selected photosensitizers are shown in Figure 1. The obtained results reveal that the EPR method leads to significant overestimation of singlet oxygen production when the singlet or triplet excited state of the photosensitizers are efficiently quenched by TEMP, acting as electron donor.

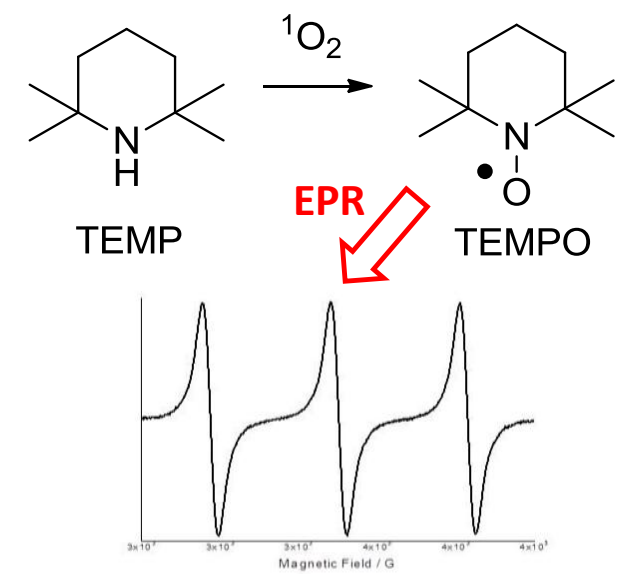<smiles>O=C1OC2(c3cc(I)c(O)c(I)c3Oc3c2cc(I)c(O)c3I)c2c(Cl)c(Cl)c(Cl)c(Cl)c21</smiles>

Rose Bengal (RB)<smiles>O=C1C=Cc2cccc3cccc1c23</smiles><smiles>O=C(c1ccccc1)c1ccccc1</smiles><smiles>c1ccc2ccccc2c1</smiles><smiles>c1ccc2c(c1)[nH]c1ccccc12</smiles>

Phenalenone (PN)

Benzophenone (BP) Naphthalene (NP)

Carbazole (CBZ)

Figure 1: Structure of the molecules involved in the study and EPR signal of TEMPO radical 


\section{Materials and methods}

\section{Chemicals}

2,2,6,6-Tetramethyl-1-piperidine (TEMP), tris(4-bromophenyl)aminium hexachloroantimonate (BAHA), phenalenone (PN), benzophenone (BZ), naphthalene (NP), carbazole (CBZ), rose Bengal (RB) and acetonitrile (ACN) were from Sigma-Aldrich. TEMP was freshly distilled at $152^{\circ} \mathrm{C}$ before use.

\section{Absorption and fluorescence spectra}

UV-vis absorption spectra were recorded on a commercial spectrophotometer $(\lambda 650$, Perkin Elmer). Fluorescence spectra were measured using $1 \mathrm{~nm}$ steps and $0.5 \mathrm{~s}$ dwell time, at right angle detection (FLSP920, Edinburgh Instruments). Slits were kept narrow to $1 \mathrm{~nm}$ for excitation and 1 or $2 \mathrm{~nm}$ for emission; where necessary, a cutoff filter was used. All the measurements were carried out at $295 \mathrm{~K}$ in quartz cuvettes with path length of $1 \mathrm{~cm}$. The fluorescence spectra were obtained for air-equilibrated solutions with $\mathrm{A}<0.1$ over the whole absorption range to avoid inner filter effects and reabsorption of emission. Quenching of CBZ and NP fluorescence intensity by TEMP upon excitation at 331 and $278 \mathrm{~nm}$, respectively, was performed by adding increasing amounts TEMP to the solution. For NP measurements, the fluorescence intensities have been corrected for the inner filter effect due to absorption of TEMP at $278 \mathrm{~nm}$. The following equation was used to determine $\mathrm{K}_{\mathrm{sv}}$, the Stern-Volmer quenching constant:

$$
\frac{F_{0}}{F}=1+K_{S V}[Q]
$$

$\mathrm{F}_{0}$ and $\mathrm{F}$ are the fluorescence intensities in the absence and presence of the quencher $\mathrm{Q}$, respectively; [Q] is the quencher concentration $(\mathrm{M}), \mathrm{K}_{\mathrm{sv}}$ the Stern-Volmer constant. The bimolecular quenching rate constant $\mathrm{k}_{\mathrm{q}}\left(\mathrm{M}^{-1} \mathrm{~s}^{-1}\right)$ was obtained dividing $\mathrm{K}_{\mathrm{sv}}$ by the fluorescence lifetime. 


\section{Fluorescence lifetimes}

Fluorescence decays were measured in air-equilibrated solutions with a time-correlated single photon counting apparatus (IBH 5000F) equipped with a TBX picosecond photon detection module. A NanoLED pulsed excitation source at 331 and $278 \mathrm{~nm}$ was used and the emission was collected at right angle at 341 or $320 \mathrm{~nm}$ using a long pass cutoff filter at $305 \mathrm{~nm}$. Fluorescence decay profiles were fitted using a monoexponential function of the decay analysis software DAS6 provided by the manufacturer with deconvolution of the instrumental response function.

\section{Laser flash photolysis measurements}

The beam of a pulsed Nd:YAG laser, operating at $532 \mathrm{~nm}$ or $355 \mathrm{~nm}(20 \mathrm{~ns}$ fwhm, $2 \mathrm{~Hz}, 2.7$ $\mathrm{mJ} /$ pulse), was suitably shaped to pass through a $3 \mathrm{~mm}$ high and $10 \mathrm{~mm}$ wide rectangular window and provide a fairly uniform energy density of $9 \mathrm{~mJ} / \mathrm{cm}^{2}$ incident onto the sample cell. A front portion of $2 \mathrm{~mm}$ depth of the excited solution was probed at right angle, the useful optical path for analyzing light being $1 \mathrm{~cm}$. All transient spectra were recorded with $3 \mathrm{~mL}$ of sample solutions in 1 $\times 1 \mathrm{~cm}^{2}$ quartz cells; when specified ACN solutions were bubbled for 10 min with Ar before data acquisition. The absorbance of the samples was kept in the range $0.30-0.40$ at the laser wavelength. Stock solutions of the quenchers were prepared, so that addition of microliter volumes to the sample cell allowed us to obtain the appropriate quencher concentration.

The bimolecular rate constant $\mathrm{k}_{\mathrm{q}}\left(\mathrm{M}^{-1} \mathrm{~s}^{-1}\right)$ for quenching of the triplet states was calculated from the slope of linear plots of the observed triplet decay rate constant $\mathrm{k}_{\mathrm{obs}}\left(\mathrm{s}^{-1}\right)$ versus the quencher concentration, applying equation 2 :

$$
k_{\text {obs }}=k_{0}+k_{q}[Q]
$$


where $\mathrm{k}_{0}$ is the triplet decay rate constant in the absence of quencher, and [Q] is the quencher molar concentration $(\mathrm{M})$.

\section{Singlet oxygen time-resolved near infrared (TRNIR) emission measurements}

The pulse of a Nd:YAG laser, operating at $355 \mathrm{~nm}$ or $266 \mathrm{~nm}$ (20 ns fwhm), was used for excitation of the samples dissolved in air-equilibrated acetonitrile. A preamplified (low impedance) Gephotodiode (Applied Detector Corp., Model 403HS, time resolution $300 \mathrm{~ns}$ ), cooled at $77 \mathrm{~K}$ and equipped with a $5 \mathrm{~mm}$ thick AR coated silicon metal filter with wavelength pass $>1.1 \mu \mathrm{m}$ and an interference filter at $1.27 \mu \mathrm{m}$, was used to measure emission of singlet oxygen at $1270 \mathrm{~nm}$ in right angle geometry. The photodiode output current was fed into a digital oscilloscope. All measurements were made at room temperature in $1 \mathrm{~cm}$ pathway quartz cuvettes. The absorbance of the samples was 0.30 at the laser wavelength. The singlet oxygen quantum yield $\left(\phi_{\Delta}\right)$ was determined using phenalenone in acetonitrile $\left(\phi_{\Delta}{ }^{\text {ref }}=0.95\right)$ as reference [30]. Singlet oxygen formation quantum yield was calculated from the slope of linear plots representing signal intensity at zero time versus laser pulse energy according to the following equation:

$$
\Phi_{\Delta}=\Phi_{\Delta}{ }^{\text {ref }} \frac{I_{\text {sample }}}{I_{\text {ref }}}
$$

where $I_{\text {sample }}$ is the emission intensity for the sample at pulse end, $I_{\text {ref }}$ is the emission intensity for the reference and $\phi_{\Delta}{ }^{\text {ref }}$ is the quantum yield of singlet oxygen formation of the reference.

\section{EPR trapping measurements}

The EPR signal of the free radical TEMPO $\left(\mathrm{g}=2.0060, \mathrm{a}_{\mathrm{N}}=17.3 \mathrm{G}\right)$ generated by reaction of singlet oxygen with TEMP was recorded [31]. The measurements were performed in a Wildman Suprasil/aqueous quartz ware flat cell (volume of $150 \mu \mathrm{L}, 60 \mathrm{~mm}$ of length) with a Bruker EMX 10/12 EPR spectrometer, using the following parameters: microwave power, $20 \mathrm{~mW}$; modulation amplitude, $1.0 \mathrm{G}$; and modulation frequency, $100 \mathrm{kHz}$. 
Aerated ACN solutions of $50 \mathrm{mM}$ TEMP containing a photosensitizer, with an absorbance of 0.4 at $280 \mathrm{~nm}$, were irradiated using the light produced by a Microbeam system (model L-201), including a $150 \mathrm{~W}$ xenon lamp coupled with a monochromator (model 101); EPR spectra were recorded at different irradiation times. The singlet oxygen quantum yield $\left(\phi_{\Delta}\right)$ was determined using phenalenone in acetonitrile $\left(\phi_{\Delta}{ }^{\text {ref }}=0.95\right)$ as reference [30]. Singlet oxygen formation was calculated from the slope of the plots of signal area versus irradiation time according to the following equation:

$$
\Phi_{\Delta}=\Phi_{\Delta}{ }^{\text {ref }} \frac{x_{\text {sample }}}{x_{\text {ref }}}
$$

where $x_{\text {sample }}$ is the coefficient of linear fit for the sample, $x_{\text {ref }}$ is the coefficient of linear fit for the reference and $\Phi_{\Delta}{ }^{\text {ref }}$ is the quantum yield of singlet oxygen formation of the reference.

In the case of tris(4-bromophenyl)aminium hexachloroantimonate (BAHA) oxidation, EPR spectra of aerated ACN solutions of $50 \mathrm{mM}$ TEMP were recorded before and after addition of 0.1 BAHA equivalents.

\section{Photoinduced electron transfer}

According to Rehm-Weller [32] the free energy change $\Delta \mathrm{G}$ for electron transfer is expressed by: $\Delta \mathrm{G}=\mathrm{E}_{\mathrm{ox}}-\mathrm{E}_{\mathrm{red}}-\mathrm{E}^{*}+\mathrm{C}$

where $\mathrm{E}_{\mathrm{ox}}$ is the oxidation potential of the donor, $\mathrm{E}_{\mathrm{red}}$ the reduction potential of the ground state acceptor, $\mathrm{E}^{*}$ the energy of the acceptor excited state and $\mathrm{C}$ is a coulombic term accounting for the electrostatic attraction of the produced ions. Neglecting the $\mathrm{C}$ term, $\Delta \mathrm{G}$ was calculated using the following values for the potentials: $\mathrm{E}_{\mathrm{ox}}(\mathrm{TEMP})=1.0 \mathrm{~V}$ and $\mathrm{E}_{\mathrm{red}}=-1.2,-1.3,-2.6$ and $-1.8 \mathrm{~V} v s$ SCE for PN [33], BP[20], NP [34] and CBZ [35], respectively. In the case of PN [36] and BP [20], the lowest triplet excited state energy was considered for $\mathrm{E}^{*}$ with values of 220 and $292 \mathrm{~kJ} \mathrm{~mol}^{-1}$, 
respectively, whereas this parameter was associated with the singlet manifold for NP [34] and CBZ [37], using values of 377 and 344 and $\mathrm{kJ} \mathrm{mol}^{-1}$, respectively.

\section{Results and discussion}

\section{Determination of singlet oxygen quantum yield by TRNIR emission or TEMPO/EPR}

Singlet oxygen quantum yields $\left(\Phi_{\Delta}\right)$ were determined for each photosensitizer with both direct method (TRNIR emission) and indirect method (TEMPO/EPR), by comparison with phenalenone $\left(\phi_{\Delta}=0.95\right)$ [30] (Figure 2). The obtained values are reported in Table 1. The results of TRNIR direct method are in accordance with literature values [37-39]. However, the quantum yield of benzophenone evaluated by indirect method TEMPO/EPR was significantly higher. This result is somewhat intriguing as, upon addition of $50 \mathrm{mM}$ TEMP to the benzophenone solution, the direct TRNIR emission measurement led to nearly zero quantum yield (Figure 2B and 3A).

Table 1: Singlet oxygen quantum yield of each photosensitizer

\begin{tabular}{lll}
\hline & $\Phi_{\Delta} / T_{R N I R^{a}}$ & $\Phi_{\Delta} / E P R^{a}$ \\
\hline Phenalenone & $0.95^{b}$ & $0.95^{b}$ \\
Benzophenone & $0.35(0.35)^{\mathrm{c}}$ & 0.50 \\
Naphthalene & $0.56(0.5)^{\mathrm{d}}$ & 0.50 \\
Carbazole & $0.15(0.17)^{\mathrm{e}}$ & 0.21 \\
$\begin{array}{l}{ }^{a} \text { in brackets, literature values, } \\
\text { [37] }\end{array}{ }^{b}$ reference, see ref [30], ${ }^{c}$ from ref [39], ${ }^{d}$ from ref [38], ${ }^{e}$ from ref
\end{tabular}



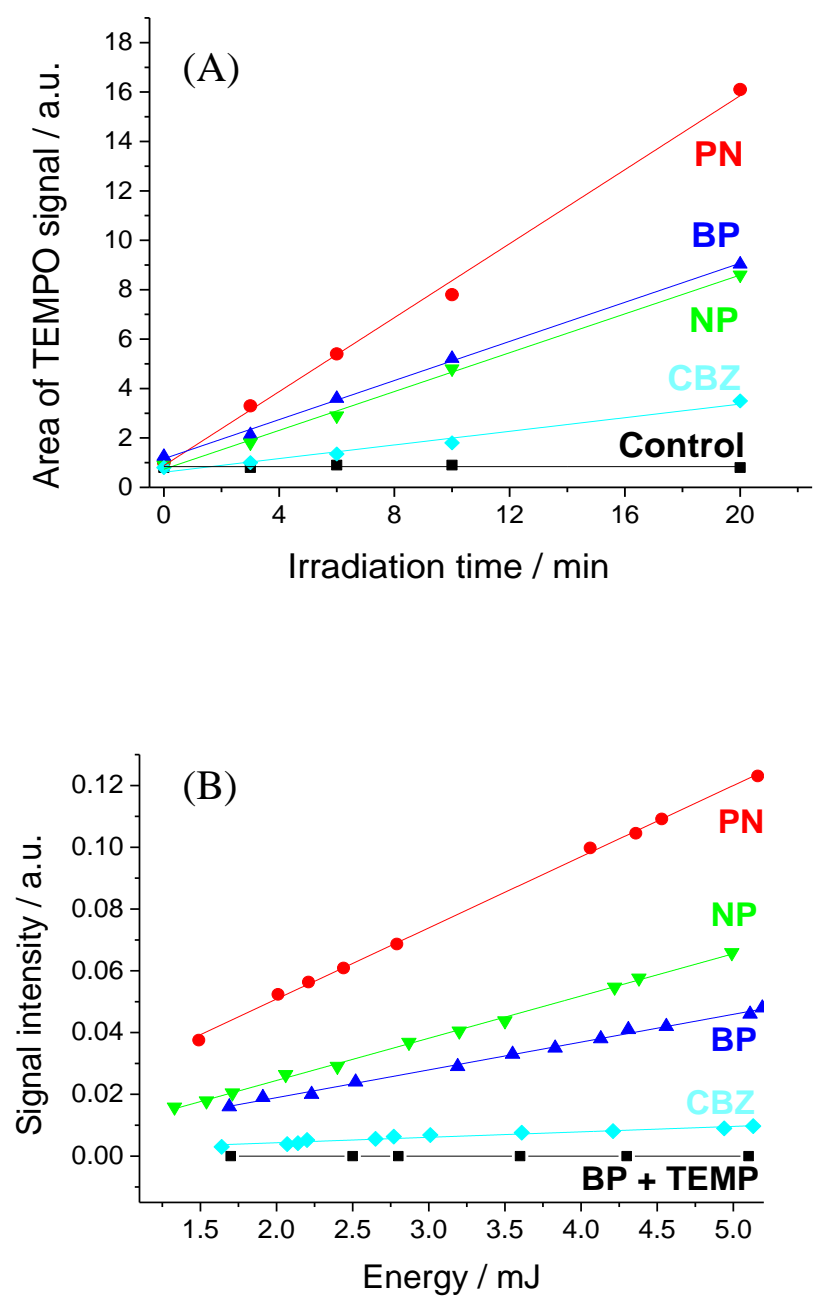

Figure 2: Quantification of ${ }^{1} \mathrm{O}_{2}$ formation for aerated acetonitrile solutions of photosensitizers. (A) Area of TEMPO signal in EPR as a function of irradiation time at $280 \mathrm{~nm}, \mathrm{~A}_{280}=0.4$ (Control: ACN solution of $50 \mathrm{mM}$ TEMP). (B) Initial intensity of ${ }^{1} \mathrm{O}_{2}$ TRNIR emission as a function of $266 \mathrm{~nm}$ laser energy, $\mathrm{A}_{266}=0.3$; in black, solution of BP and $50 \mathrm{mM}$ TEMP.

\section{Effect of added TEMP on singlet oxygen detection by TRNIR}

To investigate the direct effect of TEMP on ${ }^{1} \mathrm{O}_{2}$ production, TRNIR emission measurements were performed with photosensitizers in presence of increasing amounts of TEMP. As shown in Figure 3, in the absence of TEMP the ${ }^{1} \mathrm{O}_{2}$ lifetime was $85 \mu \mathrm{s}$ using either phenalenone or benzophenone, in accordance with the literature value [40]. Addition of TEMP to the solution had different consequences depending on the photosensitizer: in the case of phenalenone TEMP acted as a poor 
quencher, shortening the ${ }^{1} \mathrm{O}_{2}$ lifetime with $\mathrm{k}_{\mathrm{q}}=1.3 \times 10^{6} \mathrm{M}^{-1} \mathrm{~s}^{-1}$ [41], a result consistent with literature data; in the case of BP, in addition to lifetime shortening, TEMP was able to knock out the formation of ${ }^{1} \mathrm{O}_{2}$ (Figure $3 \mathrm{~A}$ ). The latter observation indicates that there is an interaction between TEMP and the precursor of ${ }^{1} \mathrm{O}_{2}$, namely the excited triplet state of BP. In the case of PN addition of TEMP did not influence the initial TRNIR signal intensity of ${ }^{1} \mathrm{O}_{2}$, while it affected the ${ }^{1} \mathrm{O}_{2}$ lifetime (Figure 3B).
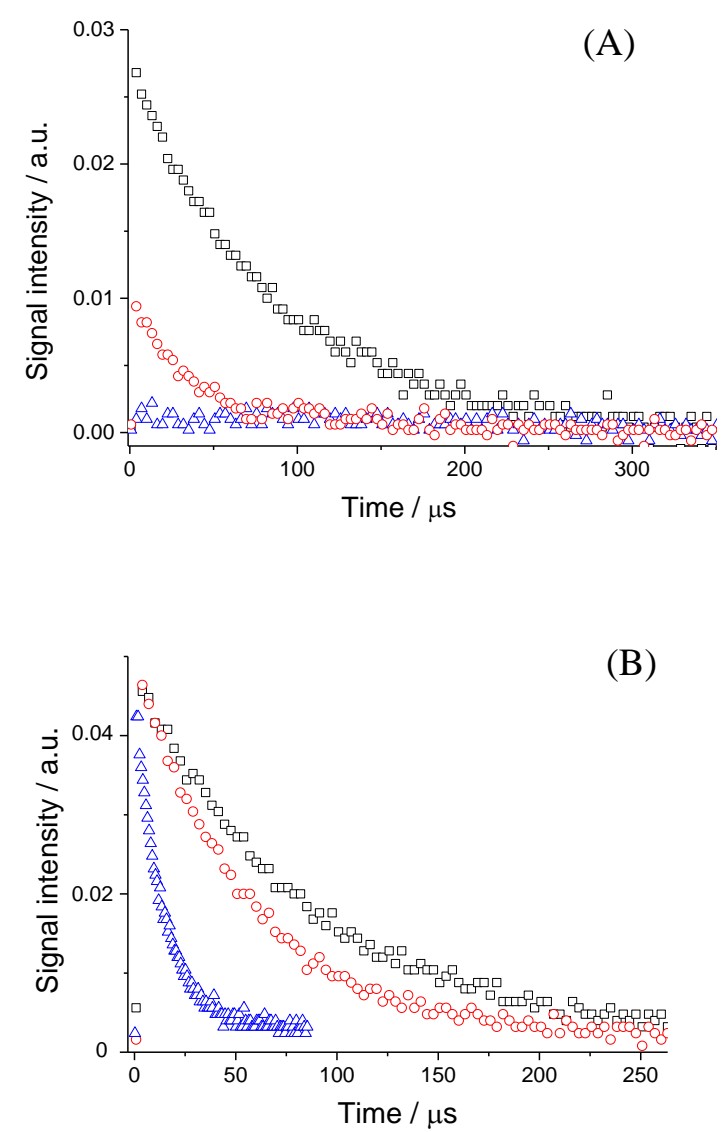

Figure 3: Luminescence decay of ${ }^{1} \mathrm{O}_{2}$ at $1270 \mathrm{~nm}$ in aerated $\mathrm{ACN}$ solution of (A) BP, (B) PN with $0 \mathrm{mM}(\square), 5 \mathrm{mM}(\circ), 50 \mathrm{mM}(\triangle)$ TEMP. Incident $355 \mathrm{~nm}$ laser energy: $3.65 \mathrm{~mJ} /$ pulse, $\mathrm{A}_{355}=0.3$. 


\section{Quenching of photosensitizer excited states by TEMP}

In view of the effects produced by addition of TEMP on the ${ }^{1} \mathrm{O}_{2}$ TRNIR signal, the triplet-triplet (TT) transient absorption of the photosensitizers was studied by laser flash photolysis in the presence of TEMP (see Figures S2-S4 in the Supplementary Material). In the case of BP, triplet quenching by TEMP was observed with rate constant $\mathrm{k}_{\mathrm{q}}=1.5 \times 10^{9} \mathrm{M}^{-1} \mathrm{~s}^{-1}$, in accordance with literature [4243]. In the case of PN, although TEMP was also able to deactivate the triplet excited state, the measured rate constant was two orders of magnitude lower $\left(\mathrm{k}_{\mathrm{q}}=8.3 \times 10^{6} \mathrm{M}^{-1} \mathrm{~s}^{-1}\right)$. On the contrary the rate constants for triplet quenching by oxygen are very similar for the two ketones (ca. $2.5 \times 10^{9}$ $\mathrm{M}^{-1} \mathrm{~s}^{-1}$ ). Taking into account the competition between TEMP and $\mathrm{O}_{2}$, as well as the $\mathrm{k}_{\mathrm{q}}$ values and the TEMP and $\mathrm{O}_{2}$ concentrations $(50 \mathrm{mM}$ and $1.9 \mathrm{mM}$, respectively), more than $90 \%$ of triplet $\mathrm{BP}$ is quenched by TEMP, whereas more than $90 \%$ of triplet $\mathrm{PN}$ is quenched by $\mathrm{O}_{2}$ under the employed conditions. This fact explains the difference between BP and PN in the singlet oxygen formation yields upon TEMP addition.

As regards NP and CBZ, weak intensity of the LFP signals makes their triplet states to be barely detected in the presence of TEMP (for example, Figure S4 in the Supplementary Material); this was attributed to scarce population of the triplet states caused by quenching of the precursor singlet excited states. To check this hypothesis, the emission signal of NP and CBZ was monitored in the presence of TEMP. The results for CBZ are shown in Figure 4A; they reveal a marked decrease of the fluorescence intensity concomitant with the growth of a new structured emission band with peaks at 400, 420, 450 and $470 \mathrm{~nm}$. This type of long-wavelength emission has been previously observed in the presence of amines and attributed to charge transfer in the excited state (excited CBZ carbanion and/or exciplex formation) [44]. The $\mathrm{k}_{\mathrm{q}}$ determined by means of steadystate and time-resolved emission measurements were $9.1 \times 10^{8} \mathrm{M}^{-1} \mathrm{~s}^{-1}$ and $6.7 \times 10^{8} \mathrm{M}^{-1} \mathrm{~s}^{-1}$, respectively (Figure S5 in the Supplementary Material). The difference between the two values suggests the contribution of static quenching, probably due to formation of a ground-state complex. 

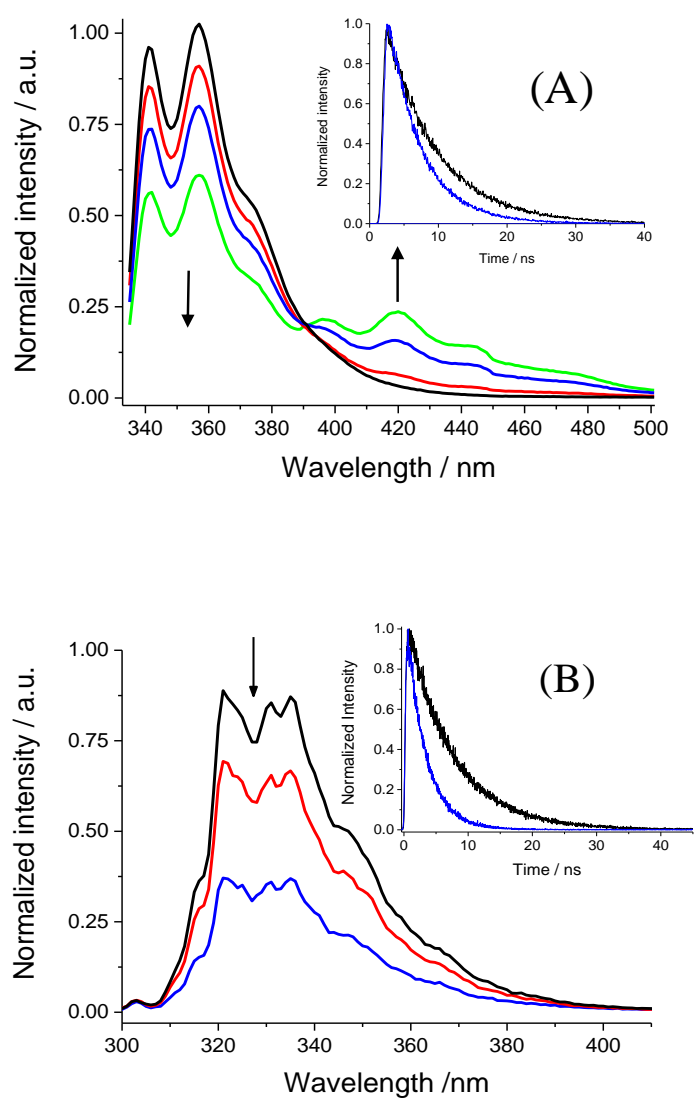

Figure 4: (A) Steady state fluorescence spectra of CBZ in aerated ACN solution with increasing amount of TEMP. $[\mathrm{CBZ}]=3.5 \times 10^{-5} \mathrm{M}, \lambda_{\text {ex }}=331 \mathrm{~nm}$. $[$ TEMP $]=0$ (black), 10 (red), 50 (blue), 100 $\mathrm{mM}$ (green). Inset: Decay of CBZ at $341 \mathrm{~nm}$ in aerated ACN solution with $0 \mathrm{mM}$ TEMP (black), $100 \mathrm{mM}$ TEMP (blue). (B) Steady state fluorescence spectra of NP in aerated ACN solution with increasing amount of TEMP. $[\mathrm{NP}]=2.3 \times 10^{-6} \mathrm{M}, \lambda_{\mathrm{ex}}=278 \mathrm{~nm}$. [TEMP] $=0$ (black), 10 (red), 50 $\mathrm{mM}$ (blue). Inset: Decay of NP at $320 \mathrm{~nm}$ in aerated ACN solution with $0 \mathrm{mM}$ TEMP (black), 50 $\mathrm{mM}$ of TEMP (blue).

Likewise, the singlet excited state of NP was quenched by TEMP (Figure 4B); the rate constant obtained from steady state fluorescence $\left(k_{q}=1.9 \times 10^{9} \mathrm{M}^{-1} \mathrm{~s}^{-1}\right.$, Figure $\mathrm{S} 6$ in the Supplementary Material) was similar to that resulting from time resolved fluorescence $\left(\mathrm{k}_{\mathrm{q}}=2.0 \times 10^{9}\right.$ $\mathrm{M}^{-1} \mathrm{~s}^{-1}$ ), indicating that NP-TEMP ground-state complexation can be safely ruled out. It should be noticed that the efficient quenching of the singlet excited photosensitizer by TEMP and the reduced ${ }^{1} \mathrm{O}_{2}$ production are not reflected in the EPR measurements of Table 1. 
Overall, the results related to excited state quenching by TEMP suggest the possibility of an alternative electron transfer reaction pathway for the oxidation of TEMP that produces a detectable TEMPO signal not involving singlet oxygen.

\section{Electron transfer oxidation of TEMP to TEMPO}

Photoinduced electron transfer (PET) is a feasible reaction between ketone or aromatic hydrocarbon photosensitizers and amines [26-29]. Being a secondary amine, TEMP ( $\mathrm{E}_{\mathrm{ox}}=1.0 \mathrm{~V}$ vs $\left.\mathrm{SCE}\right)$ [45] could be oxidized by PET if the process is thermodynamically allowed. According to Rehm-Weller [32], this requirement is fulfilled for all the investigated photosensitizers. Indeed $\Delta \mathrm{G}$ for electron transfer is in all cases negative, being of ca. $-10,-70,-30$ and $-70 \mathrm{~kJ} \mathrm{~mol}^{-1}$ for PN, BP, NP and CBZ, respectively.

To actually prove that an electron transfer reaction can contribute to the production of the TEMPO radical, TEMP was oxidized by tris(4-bromophenyl)aminium hexachloroantimonate (also named BAHA or magic blue), a known one-electron oxidizing agent $\left(\mathrm{E}_{\mathrm{red}}=1.17 \mathrm{~V}\right.$ vs $\left.\mathrm{SCE}\right)$ [46]. Addition of BAHA to a solution of TEMP in acetonitrile led to the bleaching of the initial blue color, which turned pale brown (Figure S7 in the Supplementary Material). The resulting solution was analyzed by EPR, and an enhanced TEMPO signal was observed under aerobic conditions (see Figure S8 in the Supplementary Material). The mechanistic scheme explaining these results is outlined in Figure 5. Generation of the radical cation $\mathrm{TEMP}^{+\bullet}$ is followed by deprotonation and reaction of the resulting neutral radical with molecular oxygen, finally leading to the TEMPO radical [47-49].

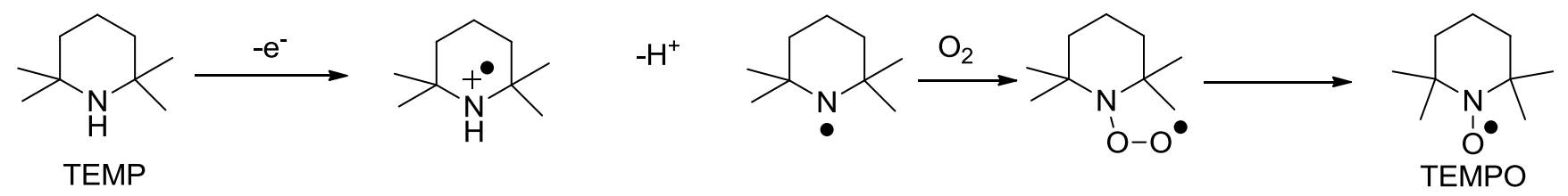

Figure 5: Proposed mechanism for the electron transfer oxidation of TEMP to TEMPO in the presence of molecular oxygen 


\section{The case of rose Bengal, an archetypal ${ }^{1} \mathrm{O}_{2}$ photosensitizer}

The methodology was applied to rose Bengal (RB), a ${ }^{1} \mathrm{O}_{2}$ photosensitizer widely used in cellular experiments. Steady-state fluorescence showed an almost unaltered emission of RB singlet excited state in the presence of $100 \mathrm{mM}$ TEMP (Figure 6A). This result is in accordance with time-resolved measurements, which allowed determining a very low quenching rate constant of ca. $10^{7} \mathrm{M}^{-1} \mathrm{~s}^{-1}$ (Figure 6A, inset). Likewise, the triplet excited state of RB was not affected by the presence of the secondary amine (Figure 6B). Thus, from these data one can anticipate that the RB singlet oxygen quantum yield obtained by the TEMPO/EPR method should correlate well with that reported in the literature $\left(\phi_{\Delta}=0.54\right)$ [50]. This was confirmed by performing the EPR experiment using PN as standard, which led to a very reasonable value of 0.56 (Figure 6C).
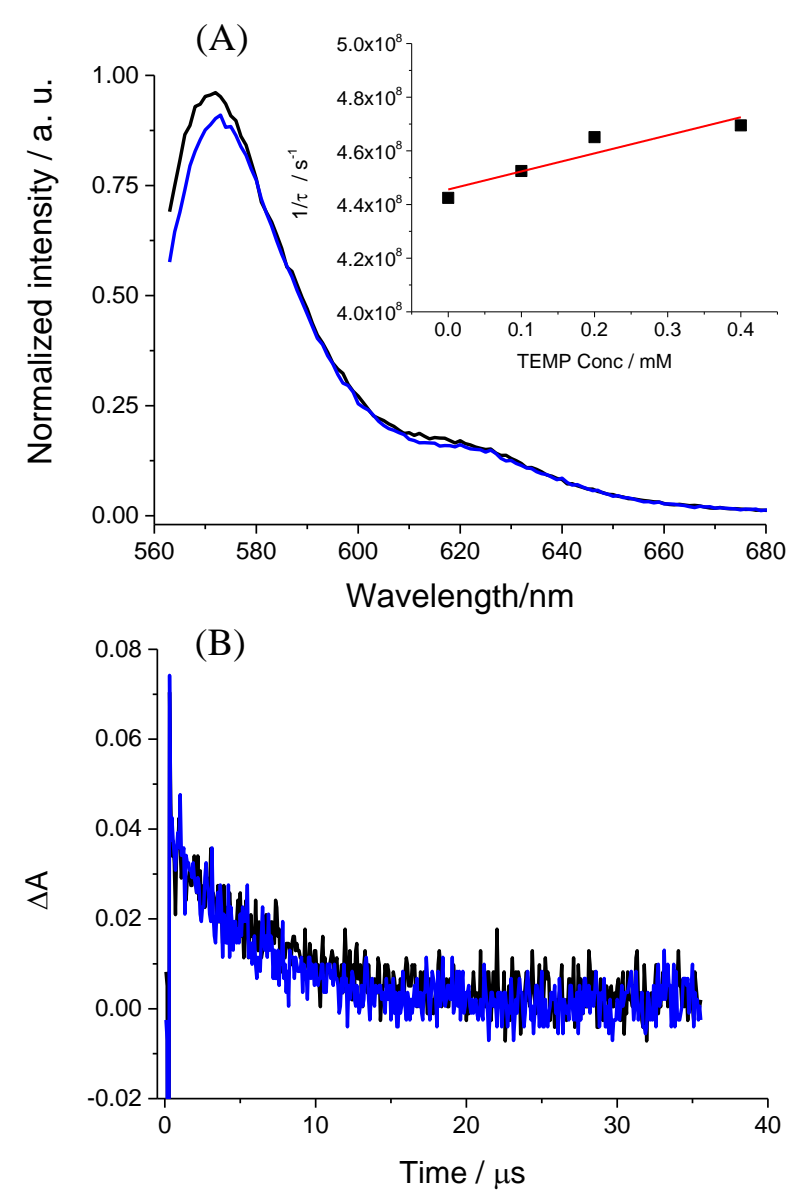


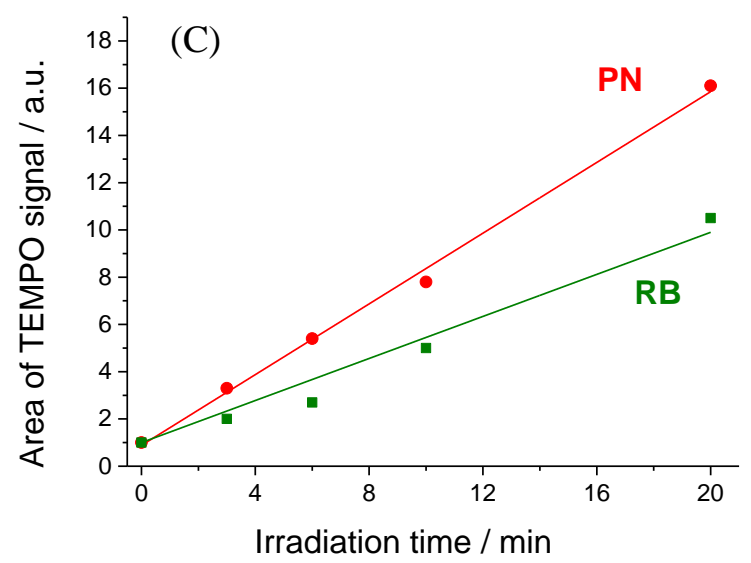

Figure 6: (A) Emission of an aerated ACN solution of RB alone (black) or in the presence of 100 $\mathrm{mM}$ TEMP (blue). $[\mathrm{RB}]=4 \times 10^{-6} \mathrm{M}, \lambda_{\mathrm{ex}}=560 \mathrm{~nm}$. Inset: Stern-Volmer plot obtained from timeresolved measurements of $\mathrm{RB}$ in the presence of increasing amounts of TEMP $\left(\lambda_{\text {ex }}=560 \mathrm{~nm}\right.$, $\left.\lambda_{\text {em }}=573 \mathrm{~nm}\right)$. (B) T-T absorption decays monitored at $620 \mathrm{~nm}\left(\lambda_{\mathrm{ex}}=532 \mathrm{~nm}\right)$ of argon-bubbled ACN solution of RB $\left(3.3 \times 10^{-5} \mathrm{M}\right)$ alone (black) or in the presence of $100 \mathrm{mM}$ TEMP (blue). (C) Area of TEMPO signal in EPR as a function of irradiation time at $280 \mathrm{~nm}, \mathrm{~A}_{280}=0.4$.

\section{Conclusion}

Detection and quantification of singlet oxygen by means of the TEMPO/EPR method is a useful and widely employed technique. This method however may be misleading when the excited photosensitizer is capable to react with TEMP, acting as an electron donor. In this case, generation of the $\mathrm{TEMP}^{+\bullet}$ radical cation, followed by deprotonation and reaction with molecular oxygen, gives rise to a EPR detectable TEMPO signal that is not associated with singlet oxygen production. The possibility of such an electron transfer interference can be anticipated by means of simple thermodynamic calculations based on redox potentials and excited state energies. In addition, this source of artifacts can be safely ruled out when no quenching of the photosensitizer singlet and triplet excited states by TEMP is observed in fluorescence and laser flash photolysis experiments, 
respectively. Thus the application of such relatively simple techniques provides knowledge that is essential for an appropriate and error-free application of the TEMPO/EPR method of singlet oxygen detection in chemical, biological and medical studies.

\section{Appendix A. Supplementary material}

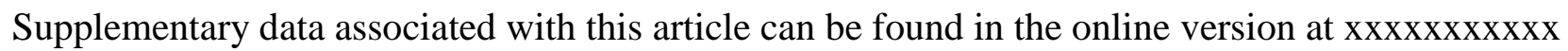

\section{Acknowledgements}

Spanish Government (CTQ2012-32621, RyC-2007-00476, PFIS FI09/00312, Severo Ochoa program SEV-2012-0267), the Carlos III Institute of Health (Grant RIRAAF, RETICS program RD12/0013/0009) and Generalitat Valenciana (Prometeo II/2013/005) are gratefully acknowledged for financial support. Dr A. Vidal-Moya is acknowledged for his help during EPR measurements.

\section{References}

[1] Shahidi, F.; Zhong, Y. Lipid oxidation and improving the oxidative stability, Chem. Soc. Rev. 39: 4067-4079, 2010.

[2] Girotti, A. W. Translocation as a means of disseminating lipid hydroperoxide-induced oxidative damage and effector action, Free Radic. Biol. Med. 44: 956-968, 2008.

[3] Hawkins, C. L.; Morgan, P. E.; Davies, M. J. Quantification of protein modification by oxidants, Free Radic. Biol. Med. 46: 965-988, 2009.

[4] Jensen, R. L.; Arnbjerg, J.; Ogilby, P. R. Reaction of singlet oxygen with tryptophan in proteins: a pronounced effect of the local environment on the reaction rate, J. Am. Chem. Soc. 134: 9820-9826, 2012. 
[5] Pattison, D. I.; Rahmanto, A. S.; Davies, M. J. Photo-oxidation of proteins, Photochem. Photobiol. Sci. 11: 38-53, 2012.

[6] Agnez-Lima, L. F.; Melo, J. T. A.; Silva, A. E.; Oliveira, A. H. S.; Timoteo, A. R. S.; Lima-Bessa, K. M.; Martinez, G. R.; Medeiros, M. H. G.; Di Mascio, P.; Galhardo, R. S.; Menck, C. F. M. DNA damage by singlet oxygen and cellular protective mechanisms, Mutat. Res. - Rev. Mutat. 751: 15-28, 2012.

[7] Cadet, J.; Douki, T.; Ravanat, J. L. Oxidatively generated damage to the guanine moiety of DNA: Mechanistic aspects and formation in cells, Acc. Chem. Res. 41: 1075-1083, 2008.

[8] Cadet, J.; Douki, T.; Ravanat, J. L. Oxidatively generated base damage to cellular DNA, Free Radic. Biol. Med. 49: 9-21, 2010.

[9] Lhiaubet-Vallet, V.; Miranda, M. A., Phototoxicity of drugs, in CRC Handbook of Organic Photochemistry and Photobiology, $3^{\text {rd }}$ Edition, ed. A. Griesbeck; M. Oelgemöller; F. Ghetti, 2012, pp. 1541-1555.

[10] Scheinfeld, N. S.; Chernoff, K.; Ho, M. K. D.; Liu, Y. C. Drug-induced photoallergic and phototoxic reactions - an update, Expert Opin. Drug Saf. 13: 321-340, 2014.

[11] Kruft, B. I.; Greer, A. Photosensitization reactions in vitro and in vivo, Photochem. Photobiol. 87: 1204-1213, 2011.

[12] Lovell, J. F.; Liu, T. W. B.; Chen, J.; Zheng, G. Activatable photosensitizers for imaging and therapy, Chem. Rev. 110: 2839-2857, 2010.

[13] Schweitzer, C.; Schmidt, R. Physical mechanisms of generation and deactivation of singlet oxygen, Chem. Rev. 103: 1685-1758, 2003.

[14] Baumler, W.; Regensburger, J.; Knak, A.; Felgentrager, A.; Maisch, T. UVA and endogenous photosensitizers - the detection of singlet oxygen by its luminescence, Photochem. Photobiol. Sci. 11: 107-117, 2012. 
[15] Ogilby, P. R. Singlet oxygen: there is indeed something new under the sun, Chem. Soc. Rev. 39: 3181-3209, 2010.

[16] Lion, Y.; Delmelle, M.; Van De Vorst, A. New method of detecting singlet oxygen production, Nature 263: 442-443, 1976.

[17] Burns, J.; Cooper, W.; Ferry, J.; King, D. W.; Dimento, B.; Mcneill, K.; Miller, C.; Miller, W.; Peake, B.; Rusak, S.; Rose, A.; Waite, T. D. Methods for reactive oxygen species (ROS) detection in aqueous environments, Aquat. Sci. 74: 683-734, 2012.

[18] He, Y.-Y.; Jiang, L.-J. Synthesis and EPR investigations of new aminated hypocrellin derivatives, Free Radic. Biol. Med. 28: 1642-1651, 2000.

[19] Kładna, A.; Aboul-Enein, H. Y.; Kruk, I. Enhancing effect of melatonin on chemiluminescence accompanying decomposition of hydrogen peroxide in the presence of copper, Free Radic. Biol. Med. 34: 1544-1554, 2003.

[20] Lhiaubet, V.; Paillous, N.; Chouini-Lalanne, N. Comparison of DNA damage photoinduced by ketoprofen, fenofibric acid and benzophenone via electron and energy transfer, Photochem. Photobiol. 74: 670-678, 2001.

[21] Rahimipour, S.; Palivan, C.; Barbosa, F.; Bilkis, I.; Koch, Y.; Weiner, L.; Fridkin, M.; Mazur, Y.; Gescheidt, G. Chemical and photochemical electron transfer of new helianthrone derivatives: aspects of their photodynamic activity, J. Am. Chem. Soc. 125: 1376-1384, 2003.

[22] Vendrell-Criado, V.; Rodríguez-Muñiz, G. M.; Cuquerella, M. C.; Lhiaubet-Vallet, V.; Miranda, M. A. Photosensitization of DNA by 5-methyl-2-pyrimidone deoxyribonucleoside: (6-4) photoproduct as a possible Trojan horse, Angew. Chem. Int. Ed. 52: 6341-6341, 2013. 
[23] Yuying, H.; Jingyi, A.; Lijin, J. Effect of structural modifications on photosensitizing activities of hypocrellin dyes: EPR and spectrophotometric studies, Free Radic. Biol. Med. 26: 1146-1157, 1999.

[24] Montanaro, S.; Lhiaubet-Vallet, V.; Iesce, M.; Previtera, L.; Miranda, M. A. A mechanistic study on the phototoxicity of atorvastatin: singlet oxygen generation by a phenanthrene-like photoproduct, Chem. Res.Toxicol. 22: 173-178, 2008.

[25] Nardi, G.; Lhiaubet-Vallet, V.; Leandro-Garcia, P.; Miranda, M. A. Potential phototoxicity of rosuvastatin mediated by its dihydrophenanthrene-like photoproduct, Chem. Res. Toxicol. 24: 1779-1785, 2011.

[26] Cohen, S. G.; Parola, A.; Parsons, G. H. Photoreduction by amines, Chem. Rev. 73: 141$161,1973$.

[27] Cossy, J.; Belotti, D. Generation of ketyl radical anions by photoinduced electron transfer (PET) between ketones and amines. Synthetic applications, Tetrahedron 62: 6459-6470, 2006.

[28] Turro, N. J.; Ramamurthy, V.; Scaiano, J. C., in Modern Molecular Photochemistry of Organic Molecules, University Science Books, Sausalito, California, 2010.

[29] Yoon, U. C.; Mariano, P. S. Mechanistic and synthetic aspects of amine enone single electron-transfer photochemistry, Acc. Chem. Res. 25: 233-240, 1992.

[30] Schmidt, R.; Tanielian, C.; Dunsbach, R.; Wolff, C. Phenalenone, a universal reference compound for the determination of quantum yields of singlet oxygen $\mathrm{O}_{2}\left({ }^{1} \Delta_{\mathrm{g}}\right)$ sensitization, J. Photochem. Photobiol., A 79: 11-17, 1994.

[31] Barbieriková, Z.; Mihalíková, M.; Brezová, V. Photoinduced oxidation of sterically hindered amines in acetonitrile solutions and titania suspensions (an EPR study), Photochem. Photobiol. 88: 1442-1454, 2012. 
[32] Rehm, D.; Weller, A. Kinetics of fluorescence quenching by electron and H-atom transfer, Isr. J. Chem. 8: 259-271, 1970.

[33] Wain, A. J.; Drouin, L.; Compton, R. G. Voltammetric reduction of perinaphthenone in aqueous and non-aqueous media: An electrochemical ESR investigation, J. Electroanal. Chem. 589: 128-138, 2006.

[34] Abad, S.; Vayá, I.; Jiménez, M. C.; Pischel, U.; Miranda, M. A. Diastereodifferentiation of novel naphthalene dyads by fluorescence quenching and excimer formation, ChemPhysChem 7: 2175 - 2183, 2006.

[35] Limones-Herrero, D.; Pérez-Ruiz, R.; Jiménez, M. C.; Miranda, M. A. Bypassing the energy barrier of homolytic photodehalogenation in chloroaromatics through selfquenching, Org. Lett. 15: 1314-1317, 2013.

[36] Oliveros, E.; Suardi-Murasecco, P.; Aminian-Saghafi, T.; Braun, A. M.; Hansen, H.-J. 1HPhenalen-1-one: Photophysical properties and singlet-oxygen production, Helv. Chim. Acta 74: 79-90, 1991.

[37] Bosca, F.; Encinas, S.; Heelis, P. F.; Miranda, M. A. Photophysical and photochemical characterization of a photosensitizing drug: a combined steady state photolysis and laser flash photolysis study on carprofen, Chem. Res. Toxicol. 10: 820-827, 1997.

[38] Abdel-Shafi, A. A.; Wilkinson, F. Charge transfer effects on the efficiency of singlet oxygen production following oxygen quenching of excited singlet and triplet states of aromatic hydrocarbons in acetonitrile, J. Phys. Chem. A 104: 5747-5757, 2000.

[39] Darmanyan, A. P.; Foote, C. S. Solvent effects on singlet oxygen yield from $\mathrm{n} \pi^{*}$ and $\pi \pi^{*}$ triplet carbonyl compounds, J. Phys. Chem. 97: 5032-5035, 1993.

[40] Jensen, R. L.; Arnbjerg, J.; Ogilby, P. R. Temperature effects on the solvent-dependent deactivation of singlet oxygen, J. Am. Chem. Soc. 132: 8098-8105, 2010. 
[41] Zang, L.-Y.; Misra, B. R.; Van Kuijk, F. J. M. G.; Misra, H. P. EPR studies on the kinetics of quenching singlet oxygen, Biochem. Mol. Biol. Int. 37: 1187-1195, 1995.

[42] Brede, O.; Beckert, D.; Windolph, C.; Göttinger, H. A. One-electron oxidation of sterically hindered amines to nitroxyl radicals: intermediate amine radical cations, aminyl, $\alpha-$ aminoalkyl, and aminylperoxyl radicals, J. Phys. Chem. A 102: 1457-1464, 1998.

[43] Zhu, Q. Q.; Schnabel, W. Interaction of triplet-excited benzophenone with hindered amines and amino ethers: A laser flash photolysis study employing photoconductivity and light emission measurements, J. Photochem. Photobiol., A 130: 119-125, 2000.

[44] Bortolus, P.; Monti, S.; Galiazzo, G.; Gennari, G. Complexation of aliphatic amines with carbazole in the So and S1 states: Solvent effect on the deactivation of the excited complex, Chem. Phys. 223: 99-108, 1997.

[45] Pischel, U.; Nau, W. M. Switch-over in photochemical reaction mechanism from hydrogen abstraction to exciplex-induced quenching: interaction of triplet-excited versus singletexcited acetone versus cumyloxyl radicals with amines, J. Am. Chem. Soc. 123: 9727-9737, 2001.

[46] Ciminale, F.; Lopez, L.; Farinola, G. M.; Sportelli, S.; Nacci, A. Acid catalysis in the aminium hexachloroantimonate-induced cyclodimerization of 1-aryl-1-phenylethylenes, Eur. J. Org. Chem. 2002: 3850-3854, 2002.

[47] Gottinger, H. A.; Zubarev, V. E.; Brede, O. Low-temperature EPR study of the reaction of the 2,2,6,6-tetramethylpiperidyl radical with molecular oxygen. Direct spectroscopic observation of an aminylperoxyl radical, J. Chem. Soc., Perkin Trans. 2: 2167-2172, 1997.

[48] Roberts, J. R.; Ingold, K. U. Kinetic applications or electron paramagnetic resonance spectroscopy. X. Reactions of some alkylamino radicals in solution, J. Am. Chem. Soc. 95 : 3228-3235, 1973. 
[49] Faucitano, A.; Buttafava, A.; Martinotti, F.; Bortolus, P. First electron spin resonance identification of a nitrogen peroxy radical as intermediate in the photooxidation of $2,2,6,6$ tetramethylpiperidine derivatives, J. Phys. Chem. 88: 1187-1190, 1984.

[50] Schmidt, R.; Afshari, E. Comment on "Effect of solvent on the phosphorescence rate constant of singlet molecular oxygen $\left({ }^{1} \Delta_{\mathrm{g}}\right) "$, J. Phys. Chem. 94: 4377-4378, 1990. 